\title{
Use of genome editing technologies for improving castor bean and guar
}

\author{
Vedpal Singh Malik
}

Received: 23 April 2013 / Accepted: 20 May 2013 /Published online: 1 June 2013

(C) Society for Plant Biochemistry and Biotechnology 2013

$\begin{array}{ll}\text { Abbreviations } \\ \text { ZFN } & \text { Zinc-finger nucleases } \\ \text { TALEN } & \text { Transcription activator-like effector nucleases } \\ \text { CRISPR } & \text { Clustered Regularly Interspaced Short } \\ & \text { Palindromic Repeats }\end{array}$

Water and energy consumption will continue to increase in parallel with increasing global population. Castor bean (Ricinus communis) is a crop that thrives in harsh environment and on marginal lands while yielding good quality of oil as biofuel. This plant also produces the powerful toxin, ricin. New tools are now available to genetically improve castor been so that it is free of toxin, grows in harsh environments on marginal soils and provide improved valuable oils.

Because of hydroxyl fatty acids, the oil of castor bean (Ricinus communis) is already used for producing highquality lubricants for jet engines and in manufacturing of paints, coatings, plastics, antifungal compounds, shampoo, and cosmetics. Castor is commercially grown in Australia, India, China, Pakistan and Brazil. Castor may be engineered to directly produce methyl esters of fatty acids (Biodiesel). It is, indeed, a taxonomic relative of Jatropha curcas, both rich in oil and belongs to Euphorbiaceae. It produces Ricin which is seven times more deadly than cobra venom. American farmers do not grow castor bean extensively — even though castor bean oil is in great demand. Castor plants that do not produce ricin and allergens could rejuvenate interest in this ignored crop.

With exploitation of the existing diversity within the genus, it may be possible to combine genes for heat tolerance, drought, disease, improved bean splitting and high oil yield.

V. S. Malik $(\bowtie)$

USDA, 4700 River Road,

Riverdale, MD 20737, USA

e-mail: vedpalms@yahoo.com
Castor may be engineered to produce seed oils with epoxy fatty acids such as vernolic (12,13-epoxy-cis-9-octadecenoic) acid that is produced in Vernonia galamensis (Cahoon et al. 2002). Epoxy oils form excellent coatings on steel and plastics and could be invaluable in the preparation of improved paints, coatings and lubricants. The castor bean has already been transformed. It has the genome of $350 \mathrm{Mb}$ and about 31,237 genes. Ricin gene family may be of about 28 genes. The analysis of this genome blue print could provide knowledge of genes that may be used to develop cultivars with deeper roots for growth with less water. Molecular methods can now identify genes that respond to drought tolerance in castor. Genes that code for aquaporin proteins may be manipulated to enhance water efficiency in crops.

Another green Gold in agriculture recently has been the Guar or cluster bean (Cyamopsis tetragonoloba) which is an annual legume and the source of guar gum. Because of the increasing demand for guar gum in hydrofracking during oil and gas exploration, price of guar split bean has been rising and are currently rupees $300 / \mathrm{kg}$. Alternatives to guar based fracking formulations are xanthan gums produced by Xanthomonas compestris. Even though Guar prices will remain volatile, it is a valuable crop since guar bean is good source of nutrition for humans and animals. Guar genome sequence could also provide valuable information for manipulation of its genome. The Xanthomonas compestris genome is already sequenced. The genes for the synthesis of guar gum may be introduced in to Xanthomonas to produce hybrid gums with superior quality which can be grown on biomass to produce new gums.

Rhizobium strains that are efficient in fixing nitrogen in association with Guar and castor are also needed.

The tools and technologies (Kim et al. 2013; Voytas 2013) are now available that should be applied to eliminate ricin and make epoxy oil in castor bean (Voytas 2013) and hybrid gums in Xanthomonas compestris. The recombinant 
DNA has reduced the genes to the level of chemicals where they can now be isolated, sequenced, chemically synthesized, mutated at will and introduced into genomes to study their effects. Homologous recombination based Gene replacement, first perfected in yeast, is applicable to many other organisms. Plant genomes are very large and introduction of modified genes into plant genomes has been challenging. The recently explored custom-designed nucleases, such as zinc-finger nucleases (ZFN) or transcription activator-like effector nucleases (TALEN) add to the toolbox for targeted modification of the plant genomes. These nucleases have DNA-binding domains that target the sequence for binding. A nuclease, which is coupled to the DNA target binding domain, introduces double-strand breaks at the targeted site. Such double stranded breaks may be repaired by error-prone nonhomologous end joining. Such breaks may also be site for homologous recombination to insert a desired sequence of choice. Since Double stranded DNA breaks are repaired by error-prone nonhomologous end-joining pathways, ZFNs are good for lossof-function gene knockouts.

Other technologies for easier editing of genome that could be applicable to crop improvement are also on the horizon. Two groups (DiCarlo et al 2013; Mali et al. 2013) are exploring new genome editing tools from clustered regularly interspaced short palindromic repeats (CRISPR), present in bacterial genomes. Microbial CRISPR enzymes and RNA from Streptococcus pyogenes and Streptococcus thermophiles was used to edit DNA in mouse and human cells. Bacterial RNA guides bacterial Cas9 nucleases to targeted loci creating specific DNA strand breaks. A new revolution in genome editions is beginning because technologies are improving fast and editing multiple sites in the same cell may now be possible.

\section{References}

Cahoon EB et al (2002) Transgenic production of epoxy fatty acids by expression of a cytochrome P450 enzyme from Euphorbia lagascae seed. Plant Physiol 128(2):615-624

DiCarlo JE et al (2013) Genome engineering in Saccharomyces cerevisiae using CRISPR-Cas systems. Nucl Acids Res 41(7):43364343

Kim Y et al (2013) A library of TAL effector nucleases spanning the human genome. Nat Biotechnol 31:251-258

Mali P et al (2013) RNA-guided human genome engineering via Cas9. Science 339(6121):823-826. doi:10.1126/science.1232033, Epub 2013 Jan 3

Voytas DF (2013) Plant genome engineering with sequence-specific nucleases. Annu Rev Plant Biol 64:327-504 